\title{
Research in Afghanistan: Innovative Strategies for Overcoming Methodological Challenges Parwez Besmel ${ }^{1}$, Frederic I. Solop ${ }^{2}$ \\ ${ }^{1} \mathrm{PhD}$, Politics and International Affairs, Northern Arizona University, S San Francisco St, Flagstaff, AZ 86001. \\ E-mail: Parwez.Besmel@nau.edu \\ ${ }^{2}$ Professor, Politics and International Affairs, Northern Arizona University, S San Francisco St, Flagstaff, AZ 86001. E-mail: Fred.Solop@nau.edu
}

\begin{abstract}
This paper examines challenges associated with conducting social science research in third world, conflict settings. Employing a qualitative, case study approach, we highlight the methodological barriers confronted by administration of Afghanistan Research Services' (a Division of Afghanistan Holding Group) Mortgage Market Assessment, a study conducted in five major Afghanistan cities. While these barriers may be viewed through the lens of western social science as threatening the validity of legitimate research, innovative accommodations in the areas of sampling, quality control and mitigation of fear and mistrust led to successful data collection efforts. This case study of research in Afghanistan, offers lessons for ambitious researchers interested in adapting standard research techniques to future work with non-western peoples living under conflict conditions
\end{abstract}

Keywords: Afghanistan; research methods; geo-spatial sampling; quality control; conflict

\section{INTRODUCTION}

Much of the literature on social science methodology is written from the perspective of researchers working within western, democratic societies. Often overlooked, however, is the extent to which social science methodologies and techniques are being implemented and adapted for use in societies with non-western people living in conflict conditions. Afghanistan has recently been the subject of significant research interest, and a source of great challenge to social science researchers pursuing answers to important research questions.

This article ${ }^{1}$ examines important research challenges recently faced by Afghanistan Research Services while administering a Mortgage Market Assessment in Afghanistan. A case study of this successful research project is rooted in primary data drawn from an open-ended questionnaire administered to field researchers ${ }^{2}$ in five major Afghan provinces where the Mortgage Market Assessment was conducted. We also draw from personal experiences of one of the authors who helped manage the Mortgage Market Assessment study in Afghanistan.

The organization of the paper is as follows. Section 1 presents a brief overview of living conditions experienced in Afghanistan post-2001. This section contextualizes the nature of the methodological questions pursued in this article. Section 2 reviews the literature on conducting social science research in non-western; conflict conditions and frames an understanding of accommodations necessary for successful implementation of the Mortgage Market Assessment research in Afghanistan. Section 3 specifically presents the methodological challenges encountered when administering the Mortgage Market Assessment and creative solutions employed to guarantee study validity.

Finally, we conclude the paper with suggestions for researchers embarking upon social science research in non-Western, conflict zones.

\section{LITERATURE REVIEW}

Researchers conducting studies in non-Western, conflict-ridden areas of the world report a host of challenges to the conduct of social science research.

Although the challenges are many, the literature suggests that these challenges cluster together under the mantels of research administration, sampling, and ethical concerns embedded within researcher/research participant interactions. These concerns are further accentuated by an environmental context characterized by fear and suspicion, the lack of free expression, poor infrastructure and rigid terrain, gender insensitivities, insecurity, ethnic/tribal tensions, quality control challenges, and the lack of complete demographic information (Goodhand, 2000; Smyth, 2001; Romano, 2006; Varughese, 2007; Cohen and Arieli, 2011; Fishstein et.al., 2012).

\footnotetext{
${ }^{1}$ An earlier version of this paper was presented at the American Association of Public Opinion Research conference, Hollywood, Florida. May 14-17, 2015

${ }^{2}$ Twelve of 20 data collectors from five provinces responded to the email survey: 3 from Kabul, 4 from Balkh, 1 from Kandahar, 2 from Nanagarhar, and 2 from Herat.
} 
Bush and Duggan (2013) argue that war zones present 'the antithesis of the methodologically desirable evaluation environment' because they are in many ways, unstable, unpredictable and less controllable (p.6). Drawing from their experiences of research in three conflict-ridden environments, Cohen and Arieli (2011) assert that methodological challenges are reflected in the researcher's 'task of identifying research populations' as well as understanding 'concerns of the human research population, and assessing the quality of information received' (p.625). Similar to Cohen and Arieli, Hear and Becher (2012) assert that in many conflict zones, particularly in developing countries, huge numbers of displaced people are on the move and difficult to contact. Internal displacement greatly impact the accuracy of census records and makes drawing samples from the general population difficult to conduct.

Another important factor affecting researcher activity is the safety and security of both researchers and research participants. While international aid organizations may be helpful in generating opportunities to speak with local residents, this strategy in itself potentially create problems and researchers must be cognizant of approaching participants in a manner that does not put lives at risk (Goodhand, 2000).

Varughese (2007) discusses problems associated with a weak infrastructure, difficult geographic terrain, and poor road conditions. These conditions make survey administration in Afghanistan quite challenging. Referring to a huge national survey conducted by the Asia Foundation in Afghanistan, Varughese (2007) asserts that the poor road conditions or even the absence of roads in areas of Afghanistan make it quite complicated for field researchers to 'reach the sampling points even when the weather was favorable' ( p.2)

We turn now to a more in-depth investigation of sampling challenges, research administration challenges, and ethical challenges to the validity of data collection projects in non-Western, conflict-based communities.

\section{Sampling}

Proportional representative sampling is the cornerstone of modern, western research. This principal recognizes the value of all individuals in a society and guarantees that everyone within a population has an equal chance of being selected to participate in a research project. While proportional, representative sampling remains the gold standard of social science research, researchers operating in non-Western, conflict areas are limited in their ability to conduct proportional representative sampling.

Refugee studies, for example, are often small-scale projects that are not conducted with representative samples of a general population. The failure to employ representative sampling techniques makes it difficult for researchers to generate broad inferences. Data findings drawn from a group of refugees registered with an aid organization or refugees residing in a specific area of a city very clearly do not represent or reflect the needs of all refugees. Findings emanating from an analysis of small, unrepresentative population samples are of little utility for understanding larger group differences (Jacobsen and Landau, 2003).

Researchers acknowledge that representative sampling is 'extremely difficult to accomplish in refugee research' (Jacobsen and Landau, 2003 p.195). Consequently, Rodgers (2004) argues for a more lax method of participants selection because the environment in which the migrants live is often 'social chaos and subversive economies where affected populations experience (a) profound sense of confusion and disorientation'. The authors suggest that researchers approach forced migrants through 'very informal, interpersonal and everyday types of encounters - or hanging out' ( $p .48$ ).

Cohen and Arieli (2011) believe the ideal sampling methodology in conflict zones is 'snowball sampling', whereby research participants are asked for additional names of friends or relatives who may be interested in participating in the research project. The thinking behind snowball sampling is that in conflict environments, 'the entire population is marginalized to some degree.' That is, it is extremely difficult to find, reach and involve research participants (Cohen and Arieli, 2011, p.423). An environment of fear and distrust permeates conflict zones, making it even harder for researchers to encourage subject participation. This importance of understanding fear and suspicion is confirmed by other researchers who argue that in societies torn by conflict, people normally tend to be self-protective and fixated on their 'personal safety and [community] survival' (Bar-Tal, 2000, p354; Clark, 2006; Cohen and Arieli, 2011). The safety of researchers is of utmost concern as well. The reality is that in conflict environments, researchers face problems of 'physical danger and personal safety' (Smyth, 2001, p. 9).

Cohen and Arieli (2011), again, argue that snowball methodology works best because it helps alleviate fear and distrust, and enhances possibilities for cooperation. Romano (2006) is most well- known for conducting research in the Middle East. He, too, advocates for snowball sampling as the best method of sampling within conflict-ridden environments. Referring to his own experiences, Romano argues that snowball sampling and the power of networking helped him reach high-level authorities and attend meetings with senior officials in Iraq.

The drawback with snowball sampling, however, is the fact that this method is time-consuming and expensive. In challenging settings, it takes an immense amount of time to adequately understand the research context, reach out to people and arrange interviews, and to earn people's trust. As a result, researchers must be flexible with their time and budget while doing research in conflict environments (Romano, 2006). Others who conduct research in the Middle East confirm that snowball sampling is the method to successfully rely upon. In a survey of political scientists doing research in the Middle East, Clark (2006) found that 89 percent prefer using snowballing sampling techniques to manage interviews and gain the trust of potential participants. 


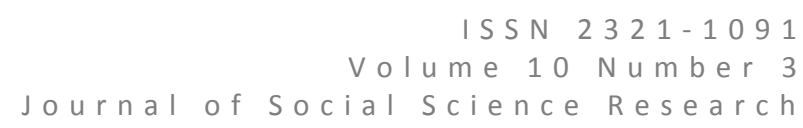

Jacobsen and Landau (2013), on the other hand, warn that snowball sampling has the potential for creating both methodological and ethical problems. Methodologically, snowball sampling runs the risk of producing sample biases. While not rooted in random sampling principle, snowball sampling relies upon information from a narrow group of respondents that share similar social networks and religious affiliations. By necessity, snowball sampling 'exclude(s) those who are not linked to the organization or individual who is at the center of the snowball' (p. 196). Furthermore, Jacobsen and Landau (2013) assert that snowball sampling enhances the danger of participants revealing important and 'potentially damaging information' about linkages between individuals and groups (p.178).

\section{Research Administration}

A basic tenant of western social science methodology is that interviewer and respondent interactions shape the quality of data collected in any research project. Adler (1983) argues that research administrators may receive a different 'response (respect, indifference, hostility)' depending upon interviewer/respondent differences in race, gender, social status, and citizenship (p. 39). Adler (1983) contends that participant response rates will vary with how the research administrator introduces the research, arranges the time and setting of data collection, and provides closing remarks. Therefore, research administration requires a thorough understanding of the context and well-planned execution of a research plan.

Jacobsen and Landau (2003) express concern about denial of access, low return rates, participant non-responsiveness, and contextual unfamiliarity as challenges that plague contemporary migration research. Because of these challenges, Jacobsen and Landau (2003) conclude that 'much of the current research on forced migration is based on unsound methodology, and that the data and subsequent policy conclusions are often flawed or ethically suspect' (p. 185).

\section{Ethical Concerns}

Methodological choices pursued by researchers working in non-Western, conflict settings are necessarily intertwined with ethical concerns. Researchers believe strongly in the need to protect confidentiality of study participants so as not to bring harm to any member of the research population (Goodhand, 2000; Jacobsen and Landau, 2003, Smyth, 2001). The ethical responsibility of 'do no harm is intensified in conflict zones' since conflict zones are necessarily defined as 'politically polarized' places where 'irresponsible armed groups are in abundance, people are traumatized and security is very precarious' (Wood, 2006, p.373). Individuals participating in research studies may 'risk arrest, torture, or execution for speaking' (Romano, 2006, p 440).

To insure the safety of the participants, Goodhand (2000) suggests that researchers must necessarily consider 'the indirect and direct impacts of research on people in war zones' and be very sensitive to the fears and needs of research populations (p.13). In challenging settings, a researcher at least 'owes that much to research participants,' Goodhand argues (p. 5). Drawing from experiences in conducting research in Afghanistan, Liberia and Sri Lanka, Goodhand (2000) believes that 'research is unlikely to be viewed by local actors as neutral or altruistic' because in conflict environment many of the interventions either by the local authority, militants or the international community are politically motivated ( $p$. 11).

In Afghanistan, for example, 'most research is donor-commissioned, often in connection with development projects or other interests'. Main funders include USAID, AusAid, DFID, GIZ, JICA, UNICEF, UNODC, UNDP, UNHCR and World Bank (Fishstein et al, 2012 p. 41). Therefore, Goodhand concludes that researchers are bound by moral responsibility to ensure they are not inadvertently harming the research population by 'infringing [their] security, privacy and well-being' (Goodhand, 2000, p.12). In studying refugees, it is difficult to control the 'doing no harm' principle because the information refugees provide through interviews or other methods may be harmful if the information is used for advocacy purposes. Jacobsen and Landau (2013) assert that in advocacy research, the 'researcher already know(s) what they want to see and say, and come away from the research having proved it' (p.187).

Bush and Duggan suggest that researchers must be concerned with the well-being and safety of research participants both during the research process and after completion of a study. There is no cookbook solution for resolving ethical dilemmas that arise in the field. 'Ethics, unlike methodology, do not easily lend themselves to standardization; no two situations are identical, and we are dealing with human morality and human behavior' (Bush and Duggan, 2013.18). Bush and Duggan also point to the risky position of researchers conducting evaluation projects in the field. If projects are financially or materially supported by an entity associated with the current government or a well-financed, western donor, the 'evaluator can expect collateral negativity and risk' (p. 10). Such is the case in Afghanistan where anyone part of a research team can be a target for their work.

Sampling, administration challenges, and ethical concerns are the main sources of challenge to conducting western, social science projects in non-Western, conflict-ridden areas of the world. Having presented literature explicating these concerns, we turn now to a focus on post-2001 Afghanistan to better understand the political, social, and economic context of the case study presented in this article.

\section{AFGHANISTAN: POST 2001 CONFLICT AND THE RESEARCH CONTEXT}

Following collapse of the Taliban regime in 2001, Afghanistan has witnessed tremendous changes politically and economically. On the political front, the country managed to hold three presidential and two parliamentary elections between 2001 and 2014. Although elections are notably contested and marked with fraud, a peaceful power transition occurred for the first time in the history of Afghanistan when President Hamid Karzai transferred power to Ashraf Ghani in 2014 following a long-disputed election. 
Today, Afghanistan structurally supports a weak form of separation of powers complemented by checks and balances that protect against institutional abuses. Economically, the country saw on average 9 percent economic growth from 20032012, based on the data from the World Bank ${ }^{3}$. Economic growth is largely a reflection of the influx of billions of dollars the country has received as foreign aid from donors including NATO and other international organizations. Today, the Afghan government is 100 percent dependent on foreign aid for internal development and 45 percent dependent on foreign aid for its overall operating budget (Development Cooperation Report, 2010).

High hopes for a better future diminished somewhat when the partial peace and stability was disturbed in some regions of Afghanistan in 2003. The Taliban, who had been defeated and excluded from political power, reorganized and resurfaced at this time. In 2003, 13 of 34 provinces, mainly in southern and eastern parts of Afghanistan, became insecure particularly for the work of the United Nations and other humanitarian organizations (Goodson, 2004). The security situation continued to deteriorate to the extent that in September 2015, Taliban forces managed to overrun Kunduz, a province in the northeast. This campaign was their first major gain since their regime fell in 2001. As security has deteriorated, civilian casualties have risen to a record high. According to the United Nations Mission in Afghanistan (UNAMA), from January 2009 to June 2015, there were '52,653 civilian casualties' including women, children and the elderly. The deteriorating situation has not only put Afghan civilians' lives at risk, but also jeopardized the work of aid agencies, national and international non-governmental organizations (NGOs), and the United Nations. According to the United Nations, from 2001-2014 Afghanistan witnessed 'the highest number of humanitarian worker casualties in the world, with 895 people attacked, including 325 killed, 253 wounded and 317 kidnapped'. ${ }^{4}$

Although internal security in Afghanistan has been deteriorating during the past 14 years, western-oriented research studies continue to be administered in this conflict zone. Many researchers believe that 'if researchers and analysts are not prepared to engage until the guns fall silent, knowledge and understanding tend to be stuck at the pre-war level' (Goodhand, 2000, p. 12). Interestingly research studies have increased in the post-Taliban world for two principle reasons: First, during the civil war and subsequent Taliban regime, Afghanistan fell away from attention by the international community. However, soon after the $9 / 11$ attack and collapse of the Taliban regime, Afghanistan become the center of international attention, overnight, there was growing need for research and information about the country. Second, there was an outpouring of billions of dollars in foreign aid from multiple donor agencies, the United Nations, private contractors and NGOs. This infusion of aid led to the birth of several large-scale national and international research and evaluation projects.

Some research agencies starting operations in post-Taliban Afghanistan have done interesting and useful research. The list includes Afghanistan Research and Evaluation Unit (AREU), Afghan Center for Socio-Economic and Opinion Research (ACSOR), SAYARA Research, RSI consulting, American Institute of Afghanistan Studies, and Afghanistan Research Services, a division of Afghanistan Holding Group that started its operation in $2014 .^{5}$

Fishsteinand and Wilder (2013) argue that in post-Taliban Afghanistan 'was in dire need of more reflective, analytical, dispassionate, and independent institution[s]' to provide relevant information to practitioners and policy makers. (p. 225). Research capacity increased due to the "combined result of revival of the education system, international academic exchanges, renewed exposure to technical and analytical fields, and the influx of donor money to fund research and analysis' (Fishstein et el., 2012, p. 1).

Like all research firms operating in war-torn zones, research entities operating in Afghanistan confront serious challenges in their ability to conduct high quality research. Some of the salient challenges Afghan research entities grapple with involve the availability and security of human resources, the lack of reliable secondary data including accurate and up-todate census information, quality control, poor infrastructure, and a prevailing atmosphere of fear and distrust due to extended conflict punctuated by frequent ethnic-based clashes.

In the last 14 years, although opportunities were presented to some Afghans to acquire higher education and other forms of training outside of Afghanistan, most of the research and evaluation projects continue to be designed, analyzed and administered by foreign experts trained in western social science methodology. Afghan universities are teaching institutions, and their graduates continue to lack the knowledge and skills required to independently run research projects. Contributions by Afghan researchers to major research projects are typically limited to data collection and middle management responsibilities.

Research entities operating in Afghanistan have a difficult time maintaining a large pool of field researchers. They hire and train field researchers from various localities on a project-by-project basis. Human resource constraints get more complicated with cultural restrictions on the roles of women (Varughese, 2007; Fishstein et el., 2012; Fishsteinand and Wilder, 2013). On the one hand, it is quite difficult to find women capable of collecting data in remote areas in Afghanistan,

\footnotetext{
${ }^{3}$ Afghanistan in Transition: Looking Beyond 2014 is a World Bank released in 2012. The report can be accessed at: http://mfa.gov.af/Content/files/Vol1Overview8Maypm.pdf

${ }^{4}$ More information on humanitarian worker casualties can be found at the $: \leq \mathrm{http}: / /$ www.un.org/press /en/2014 /sc11524 .doc.htm>
}

\footnotetext{
${ }^{5}$ Afghanistan Holding Group (AHG) was established in 2009 with it's headquarter in Kabul, Afghanistan. AHG offers services in the areas of research, financial, technology, procurement and compliance.
} 


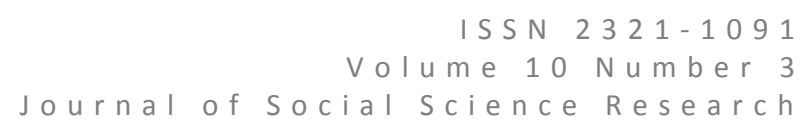

particularly in southern and eastern Afghanistan. On the other hand, women are desperately needed to perform this role, as there is a culture of segregation between men and women. Potential women respondents will not speak with nonrelated men asking probing questions, even within the city limits of more open and better-educated cities such as Kabul, Mazar-e. Sharif and Herat. Government offices, foreign embassies, the United Nations, national and international nongovernmental organizations are exceptional, as they have created the environment where women can more openly talk to male researchers.

To better capture the voices of women, research firms often recruit female data collectors from major cities. Some of these women will travel to remote areas with a family member, as it is not safe for women to travel alone. The male family members that accompany female researchers are called Mahrm. This implies a male direct relative like brother, father, son, uncle or aunt.

Alongside this human resource issue, lack of access to secondary data in Afghanistan makes the work of researchers more challenging. Government institutions, in particular at the local level, rarely make data publicly available, even if the data exists. In some provinces, there are no proper mechanisms for archiving and organizing public data. For example, in 2014, in a research mission to Badakhshan, a province in the northeast, one of the authors of this article found that the local commerce department not only lacked public data, department administrators had no clue about the amount of import and export activity taking place within the province.

Most researchers in Afghanistan rely on reports and research studies done by the United Nations, NGOs and other western institutions like the World Bank and the International Monetary Fund. Furthermore, Afghanistan has not been able to conduct a national census for the last 36 years. The last time the government conducted a census was in 1979 (Varughese, 2007). Lack of up-to-date census data makes generating a sampling frame quite complicated, if not impossible. Researchers too often rely upon old census figures or on speculative figures used by the United Nations or other prestigious international organizations, when generating sampling frames.

Quality control over data collection is another challenge that directly results from insecurity, cultural constraints, poor infrastructure, and lack of capacity of dominant research institutions. When a research study is conducted in an insecure area, such as in areas under Taliban control, research institutions defer to field researchers by assuming field reporting is highly accurate. There is no independent verification of data being absent from fraud or tampering. No one can verify, for example, that the field researcher has not completed questionnaires in his/her home. In addition, out of fear of the Taliban and other militant groups, researchers normally avoid taking electronics such as tape recorders or telephones with GPS technology to insecure areas. Although research institutions ask field researchers to record respondent phone numbers, respondents typically prefer to not give their phone numbers to strangers. Thus, phone-based verification of data quality is largely unachievable.

Finally, a prevailing atmosphere of fear and distrust in Afghanistan taints research quality. Largely due to the weak rule of law, fear and insecurity, internal ethnic rivalries, and poverty, people are fearful. They are fearful of governmental agencies, the Taliban, and irresponsible armed groups. In many instances, ruling regimes, whether the pro-communist Mujahidin or the Taliban, have turned the state machinery against their own citizens. Internal strife has not only destroyed the physical infrastructure of the country, it has also ruined societal cohesion, and eroded unity and trust among multiethnic and multi-lingual residents. When a stranger knocks on a door of a house and asks to speak with a household member, many questions cross the mind of the person opening the door. The dominant atmosphere of fear and distrust makes the work of researchers very challenging.

These challenges do have implications for research methodology and ethics. Fishsteinand and Wilder, who worked for AREU in Afghanistan, commented:

'In the complex, chaotic and unstable environment in Afghanistan, AREU's guiding principles were practicality and flexibility. While some of the solutions (e.g., a relative accompanying female research staff, service-providing NGOs acting as intermediaries, sampling based on pragmatic calculations rather than rigid sampling frames, holding interviews in public places) were not always ideal in terms of research methodology, they were judged to be the best choices in that environment.' (Fishsteinand and Wilder, 2013, p.238).

In addressing these challenges, research institutions such as AREU have erred on the side of flexibility and necessarily adapted research methodologies that are innovative in the face of adversity. We discuss innovative strategies within the context of a case study in the next section.

\section{CASE STUDY: MORTGAGE MARKET ASSESSMENT AND INNOVATION}

Afghanistan Research Services, a Division of Afghanistan Holding Group (henceforth AHG), was commissioned by HARAKAT- Afghanistan Investment Climate Facility Organization, in 2013 to conduct a Mortgage Market Assessment in Afghanistan's five major cities of Kabul, Jalalabad, Herat, Kandahar and Mazar-i-Sharif. The goal of the research was to assess investment needs in the housing sector as well as the magnitude of personal demand for mortgage loans. To gauge public demand for mortgage loans, AHG conducted a household survey of 1959 homes in the five major cities. Additionally AHG conducted 30 in-depth, stakeholder interviews, 3 focus groups with relevant government and private sectors employees including realtors, and case studies of mortgage demand in five countries: India, Pakistan, Nepal, United Arab Emirates and Malaysia. As a seasoned researcher, AHG's lead research designers was familiar with the research environment in Afghanistan and well acquainted with potential research challenges particularly pertaining to sampling, quality control and research ethics. These challenges were tackled head on in the methodological planning 


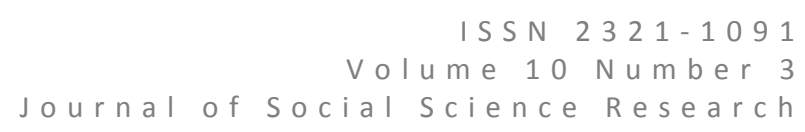

phase of the research, prior to conducting fieldwork. AHG implemented innovative methodological techniques that helped minimize threats to validity in each of these challenging areas. A description of these techniques is presented in the next section of the paper.

\section{Sampling}

Survey sampling is often hampered in developing countries by the lack of reliable population data. As Landry and Shen (2005) note, 'in the absence of census data, equal probability samples of Kabul, Phenom Penh, or Kinshasa are impossible' (p.4). In Afghanistan, researchers still rely upon results from an incomplete census dating back to 1979 . This data continues to form the 'basis for extrapolations that affect policymaking' (UNFPA Afghanistan, 2015) ${ }^{6}$. Unfortunately, for example, Afghanistan does not know the real size of its population today. Further complicating the availability of population figures is the influx of immigrants, returnees, and internally displaced people whose movements are also not well documented. Some estimates suggest the size of the internally displaced population (IDP) residing in major Afghan cities may be as large as 2 million people.

In the absence of a reliable sampling frame in Afghanistan, AHG conducted geospatial sampling, while working with an American company, Digital Globe. Landry and Shen (2005) consider geo-spatial sampling as an ideal alternative approach for countries that lack reliable population records. According to Landry and Shen (2005), if 'properly administered, spatial samples can provide a universal tool to produce equal probability samples of any population, regardless of the quality of census data or any official population count' (p.5).

Digital Globe used satellite imagery of night lights combined with movement and regular imagery to determine population density in the five major cities of Afghanistan pre-selected for inclusion in the Mortgage Market Assessment study. Following the collection of satellite imagery, areas that were either public places (e.g., government buildings, wedding halls, universities' dormitories, prisons and shops) or areas with no residential population were eliminated from the sampling frame. Elimination of this type helped ensure that the geospatial sampling frame was accurate by making sure that each site was populated by individuals who could respond to the survey.

After the clean-up process, the sample was divided into small blocks of 50 square meters and each block was assigned a unique number. The Microsoft Excel random generator function was employed to generate a sample of blocks that would provide data with a 5 percent margin of error at a 95 percent confidence level. Data collectors were subsequently provided with satellite images of the sampled blocks along with the GPS coordinates to survey every house in each of the selected blocks. Use of geospatial sampling allowed AHG to construct a reliable probability sample for the study. Through use of geospatial sampling, AHG undoubtedly addressed the sampling problem with a fresh, new solution. This solution challenged traditional techniques of sampling and is relatively new to the donor community.

\section{Research Administration}

Quality control of survey data is always a major concern when administering research in Afghanistan. Two factors complicate quality control. First is physical insecurity. Insecurity makes direct monitoring of field researchers impossible at times. Second is impact of poor infrastructure on data collection, in particular when sampling blocks are located a distance from each other. One common way of ensuring data collection quality is calling respondents and asking if data was collected from the intended subjects. However, in the Afghan context, this is simply not achievable. Although Afghanistan has made huge stride in expanding its telecommunication sector over the last decade (to date, there are over 23 million users of cell phones, ${ }^{7}$ ) due to an environment of mistrust and fear, people are reluctant to provide their cell phone numbers to an unknown field researcher. Callback processes are hampered in Afghanistan because of a prevailing culture of fear and mistrust.

To address this quality control problem, AHG used smartphones embedded with GPS technology. AHG contracted a United States-based company, IST Research, to assist with making survey software functional in the Afghan national languages of Pashto and Dari. The software developed by IST was placed onto smartphones to allow respondents to answer survey questionnaires in their preferred language. Mortgage Market Assessment survey data was saved onto the smartphones and automatically sent to an online database once phones could access an Internet connection. The use of smartphones allowed for more accurate and dependable data collection in the challenging environment of Afghanistan. The GPS technology further enabled lead researchers to visually check the location of data collection, allowing for verification that surveys were collected in proper pre-determined areas. The design of the survey allowed additional layers of quality control in the field by recording the start and end time of each survey and automatically moving respondent screens to the next relevant question. Finally, the design allowed the data to automatically upload to a cloud server, eliminating data entry errors associated with entering data manually. Creative use of technology thus helped enhance quality control and reduce human error.

\section{${ }^{6}$ For an overview of the UNFPA Afghanistan please look at: http://countryoffice.unfpa.org/afghanistan/2015/02/19/11532/linking population policies and development/}

\footnotetext{
${ }^{7}$ Based on the information available at the website of the Afghan Ministry of Telecommunication and Information Technology, currently there are 23.21 million cell phone users in Afghanistan. This is surprisingly a huge accomplishment to the Afghan government, the private sectors as prior to Karzai Administration in 2001 there was no cell phone users in Afghanistan as the technology, and the infrastructure was not in place in the country.
} 


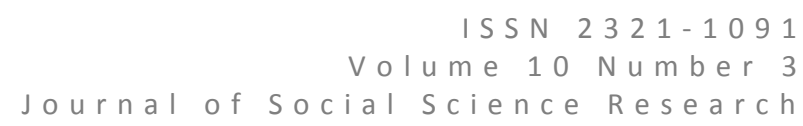

\section{Research Ethics}

War is always associated with a prevailing environment of fear and mistrust. Fear and mistrust continue to haunt people for many years after conflict is ended. In Afghanistan, fear and mistrust is compounded with an ongoing war of terror promoted by tribal and ethnic rivalries. Although there are no accurate figures on the number and size of ethnic groups, speculative figures suggest that Pashtuns constitute 38 percent of the Afghan population, followed by Tajiks (25\%), Hazaras (19\%), Uzbeks (6\%), with smaller ethnic groups such as Pashaie, Turkman, Baluch, Nuristani and others, making up the remaining 12 percent of the population (Riphenburg, 2005, p.37). Although intermarriages across various ethnic groups, particularly among Pashtuns and Tajiks, encourage people to live together peacefully, political elites sometimes trigger ethnic rifts as a means to gain and maintain power. The social structure, in particular ethno-linguistic differences between tribal peoples, has implications for doing research in Afghanistan. If a research project is being conducted in central Afghanistan, a research firm needs to design data collection instruments in Dari language and ideally employ researchers who speak Dari and preferably from Hazara ethnic group. If research is being conducted in Kunar or Paktia provinces, research instruments must be in Pashto and the data collector should be Pashton and preferably from the local people.

Working to earn the trust of the research subjects in various communities across Afghanistan and ensuring quality research work, AHG has established a working relationship with the National Association of Science and Mathematics Educators of Afghanistan (NASMEA). Association members are science and math educators mainly teaching at various universities throughout Afghanistan. AHG hires educated NASMEA members on a temporary basis to conduct field research.

For the Mortgage Market Assessment, all field researchers were NASMEA members from the Kabul Education University, Balkh University, Nangarhar University, Herat University, and Kandahar University. These universities are located in the major cities of each province being studied and the instructors of these universities are respected members of these localities. As educated faculty, NASMEA members are very familiar with techniques of social science research methodology. They are also cognizant of the importance of careful, precise, accurate data collection. For the Mortgage Market Assessment, field supervisors received training in Kabul at the headquarters of AHG. Fully trained on the use of smartphone technology and maps, field supervisors were dispatched to the five major cities to conduct trainings with NASMEA members. Trainings were offered at the universities where the members were employed. In total, 20 NASMEA members were trained and subsequently collected data for the Mortgage Market Assessment study.

AHG's partnership with NASMEA proved useful for two primary reasons. Frist, NASMEA members are faculty who understand the importance of research studies. While monetary compensation was a motivation for their service, NASMEA members performed the service with passion and responsibility knowing the significance and impact of Mortgage Market Assessment in future policy formulation by the Afghan government and private sectors. Second, being from the local communities, NASMEA members were very familiar with various culture including languages of the communities being studied. They knew how best to approach the people in the communities and were able to earn the trust of the communities in Afghanistan.

\section{SUMMARY}

While the Mortgage Market Assessment was completed in a technically sound and transparent manner, some issues reported by field researchers are worth highlighting. Field researchers reported having difficulty locating assigned places highlighted on the maps. This is because in Afghanistan, main areas have names, but most roads and streets within an area do not have names. Data collectors had a difficult time locating pre-determined data collection points. In addition, many areas within major cities are unmapped or include irregular houses (i.e. self-made residential houses,) built without properly planning or municipality management. When field researchers failed to locate the exact residential location, they were instructed to instead survey the closest residential areas following consultation with field supervisors. The field researchers in Kandahar, furthermore, reported changing some of the pre-determined areas due to insecurity. In Kabul, field researchers reported not being able to survey some of the pre-determined blocks because rich people and state officials had security guards stationed around their houses and data collectors were not allowed to enter alleys. In this circumstance, data collectors surveyed adjacent alleys.

While there were problems with locating pre-determined data collection points, field researchers reported that being locally based, university instructors helped make data collection smoother. First, data collectors were familiar with the culture of the provinces to which they were assigned. Second, data collectors had social influence in communities being studied because they are highly respected members of the society. Third, field researchers understand the logistics of research and were trained to properly approach research participants and request answers to questions. According to field researchers of the Mortgage Market Assessment, one approach was to seek assistance from community elders, including representatives and Imams of mosques. Field researchers requested the company of these respected elders to mitigate against community mistrust and fear. One of the field researchers in Kabul reported seeking help from ally representatives, shopkeepers and even kids playing in the alleys to accompany him to the houses so that the households particularly with women trust him and participate in the surveys. Otherwise, it would have been difficult, if not impossible, to interview women behind closed doors due to the social and cultural traditions of the people in Afghanistan.

While data collection generally proceeded smoothly, there were instances when field researchers did experience mistrust and fear from research participants. The data collectors reported that respondents in these instances identified the researchers as government workers assessing their properties and income. In addition, field researchers in Kabul, 


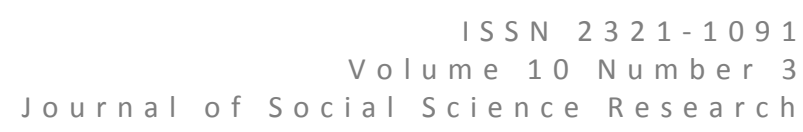

Nangarhar, Herat and Kandahar reported that due to cultural constraints, it was difficult convincing women to participate in the study. In contrast, however, field researchers in one city, Mazar-i- Sharif, reported that a high rate of women participated in the study. The reason for women's participation in Mazar-i- Sharif was not because women in Mazar are more open to participating in surveys than women of Kabul. The reason was that field researchers in Mazar-i- Sharif were women themselves. Based on the final report of the Mortgage Market Assessment, women's participation reached 39 percent in Mazar-i- Sharfi. The lowest proportion of female respondents was in Kandahar with only 3 percent of participants being women ${ }^{8}$. In total, 84 percent of research participants were male and only 16 percent of participants were female.

\section{DISCUSSION}

By their very nature, in-depth case studies of any one-research project highlight specific challenges of a nuanced environment confronted by researchers. Presentation of a case study of research in Afghanistan, however, yields valuable understanding of need for researchers to be flexible when confronting specific challenges. Research must assume a flexible stance regarding the application of western, social science principles in a very challenging environment. We believe this analysis of research in non-Western, conflict zones will help guide future researchers in their endeavor to collect high quality information about important research questions, while also protecting the lives of research participants and researchers operating in the field. We respect the work of all researchers confronting challenges such as those documented in this article, and we join these researchers in working toward doing the best job possible under the most difficult of conditions.

Innovative measures in the area of sampling, research administration, and ethics proved useful when conducting the Mortgage Market Assessment study in Afghanistan. Geospatial sampling, use of smartphone embedded GPS technology, and data collection conducted by NASMEA members helped address major concerns pertaining to the sampling, quality control and mistrust/ fear held by research subjects, and led the research project to successful completion.

\section{REFERENCES}

[1] Adler, N.J., 1983. A typology of management studies involving culture. Journal of international business studies, 14(2), pp.29-47.

[2] Bar-Tal, D., 2000. From intractable conflict through conflict resolution to reconciliation: Psychological analysis. Political Psychology, 21(2), pp.351-365.

[3] Bush, K. and Duggan, C., 2013. Evaluation in conflict zones: Methodological and ethical challenges. Journal of Peacebuilding \& Development, 8(2), pp.5-25.

[4] Clark, J.A., 2006. Field research methods in the Middle East. PS: Political Science \& Politics, 39(03), pp.417-424.

[5] Cohen, N. and Arieli, T., 2011. Field research in conflict environments: Methodological challenges and snowball sampling. Journal of Peace Research, 48(4), pp.423-435.

[6] Afghanistan Ministry of Finance. Development Cooperation Report 2010.

[7] Fishstein, P., Paterson, A. and Roe, A., 2012. Mapping of Research Capacity in Afghanistan. Department for International Development: Government of the United Kingdom.

[8] Fishstein, P. and Wilder, A., 2013. Establishing a Policy Research Organization in a Conflict Zone The Case of the Afghanistan Research and Evaluation Unit. Research Methods in Conflict Settings: A View from Below, p.223.

[9] Goodhand, J., 2000. Research in conflict zones: ethics and accountability. Forced Migration Review, 8(4), pp.1216.

[10] Goodson, L.P., 2004. Afghanistan in 2003: the Taliban Resurface and a new Constitution is born. Asian Survey, 44(1), pp.14-22.

[11] Jacobsen, K. and Landau, L.B., 2003. The dual imperative in refugee research: some methodological and ethical considerations in social science research on forced migration. Disasters, 27(3), pp.185-206.

[12] Landry, P.F. and Shen, M., 2005. Reaching migrants in survey research: the use of the global positioning system to reduce coverage bias in China. Political Analysis, 13(1), pp.1-22.

[13] Mathee, A., Harpham, T., Naicker, N., Barnes, B., Plagerson, S., Feit, M., Swart, A. and Naidoo, S., 2010. Overcoming fieldwork challenges in urban health research in developing countries: a research note. International Journal of Social Research Methodology, 13(2), pp.171-178.

[14] Nasif, E.G., Al-Daeaj, H., Ebrahimi, B. and Thibodeaux, M.S., 1991. Methodological problems in cross-cultural research: An updated review. MIR: Management International Review, pp.79-91.

[15] Protection of Civilians in Armed Conflict: Afghanistan Mid-Year Report 2015. United Nations Mission in Afghanistan.

[16] Riphenburg, C.J., 2005. Ethnicity and civil society in contemporary Afghanistan. The Middle East Journal, 59(1), pp.31-51.

\footnotetext{
${ }^{8}$ This is based on the final report of the Mortgage Market Assessment in Five Major Cities of Afghanistan. The full report can be accessed at: http://www.harakat.af/site_files/14011678611.pdf
} 


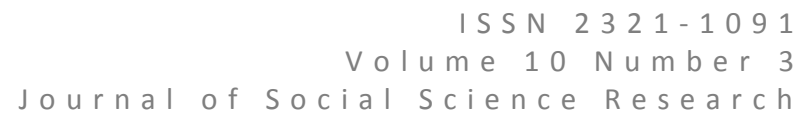

[17] Rodgers, G., 2004. Hanging out with forced migrants: methodological and ethical challenges. Forced migration review, (21), pp.48-49.

[18] Romano, D., 2006. Conducting research in the Middle East's conflict zones. PS: Political Science \& Politics, 39(03), pp.439-441.

[19] Sekaran, U., 1983. Methodological and theoretical issues and advancements in cross-cultural research. Journal of International Business Studies, 14(2), pp.61-73.

[20] Smyth, M. and Robinson, G., 2001. Researching violently divided societies: Ethical and methodological issues. Pluto Press.

[21] Varughese, G., 2007. Practical challenges: Conducting survey research in Afghanistan. Retrieved July, 30, p.2012.

[22] Wood, E.J., 2006. The ethical challenges of field research in conflict zones. Qualitative Sociology, 29(3), pp.373386.

\section{AUTHORS' BIOGRAPHY WITH PHOTOS}

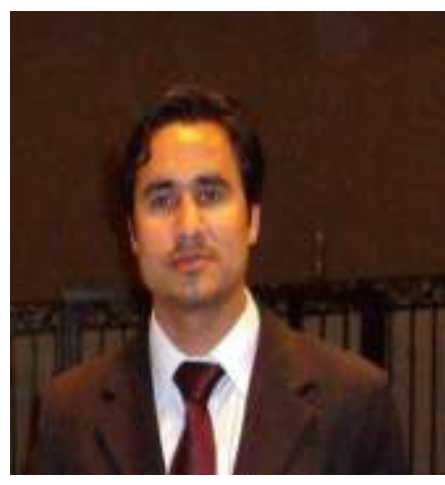

\section{Dr. Parwez Besmel, Ph.D.}

Parwez Besmel holds a PhD in Politics and International Affairs from Northern Arizona University. His experience includes serving as Adjunct Faculty in the Department of Politics and International Affairs at Northern Arizona University, Research Associate for Creative Associates International/ USAID's BESST Project, Lecturer at School of Languages and Literature Kabul University; Director of Foreign Relations and Cultural Affairs at Kabul University, External Relation Consultant with the Asia Foundation and Correspondent for Reuters News Agency.

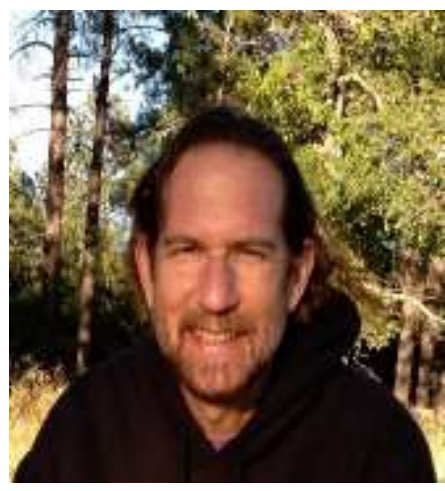

\section{Dr. Frederic I. Solop, Ph.D.}

Dr. Solop is a professor in the Department of Politics and International Affairs at Northern Arizona University. He has served two terms as department chair (2008-2011, 2013-2014), and served as director of NAU's Social Research Laboratory from 19992008. As director of the SRL, Dr. Solop regularly conducted research with national, state, and regional governmental agencies and units, as well as non-profit organizations. Dr. Solop publishes frequently in the areas of research methods, public opinion, political participation, and digital democracy. 